Este libro forma parte del acervo de la Biblioteca Jurídica Virtual del Instituto de Investigaciones Jurídicas de la UNAM

\title{
RETOS JURÍDICOS DE LA PANDEMIA
}

\author{
José Ramón Cossío DíAZ \\ David Jesús SÁNCHEZ Mejía
}

\begin{abstract}
SUMARIO: I. Introducción. II. El federalismo en la atención de una epidemia. III. Instituciones para responder a una epidemia grave. IV. La atención a la epidemia del virus SARS-CoV-2 en México. V. Conclusiones.
\end{abstract}

\section{INTRODUCGIÓN}

El pasado 24 de junio de 2020 fuimos invitados a participar en el "Coloquio virtual: COVID-19 y Bioética" convocado por la Universidad Nacional Autónoma de México mediante los institutos de Investigaciones Jurídicas y de Investigaciones Filosóficas. Nuestras participaciones, aunque se dieron en mesas distintas, tocaron preocupaciones comunes en torno a las herramientas con las que cuenta el Estado mexicano para hacer frente a un fenómeno como el que vivimos y a las normas existentes para emplearlas.

En el presente artículo expondremos cómo se trata una epidemia desde el sistema federal. La comprensión de la concurrencia de las facultades que tiene la Federación como las entidades federativas resulta indispensable para poder adentrarnos en el análisis de las posibles modalidades e instituciones que deben estar a cargo de la respuesta. En este sentido, en el primer apartado analizaremos cuál es marco aplicable a una enfermedad transmisibles como es COVID-19, para después identificar si normativamente existen diversas modalidades o características en que se pueda presentar una epidemia. A partir de esto, podremos identificar cuáles son las facultades de cada orden jurídico para una u otra de las modalidades identificadas.

En el segundo apartado expondremos los orígenes y alcances de los órganos del Estado mexicano para responder a una epidemia de las características que ha adquirido la del virus SARS-Cov2. El tercer apartado haremos un relato de los actos jurídicos que se han realizado para ordenar 
Este libro forma parte del acervo de la Biblioteca Jurídica Virtual del Instituto de Investigaciones Jurídicas de la UNAM

la epidemia y llevar a cabo la correspondiente contención. En particular se enfatizará el análisis de algunos aspectos que resultan controvertidos, así como algunas de sus posibles causas.

Finalmente, presentaremos a manera de conclusiones algunas propuestas que, desde nuestra óptica, permitirían que el Estado se encuentre mejor preparado y traslade el aprendizaje de la crisis presente a normas que faciliten una respuesta rápida y efectiva a otra epidemia o a otros desafíos en materia de salud pública.

\section{EL FEDERALISMO EN LA ATENCIÓN DE UNA EPIDEMIA}

La Ley General de Salud (LGS) establece las bases y modalidades para el acceso a los servicios de salud, así como la concurrencia entre la Federación y las entidades federativas respecto a las materias de salubridad general, tal como lo dispone el artículo 4o. constitucional.

Para comprender la manera en que desde el federalismo debe tratarse una epidemia como la del virus SARS-Cov2 causante de Covid-19, es indispensable conocer, en primer término, si este tipo de enfermedades son consideradas como una materia de salubridad general; en segundo término, cuáles son las facultades de los distintos niveles de gobierno para atenderlas $\mathrm{y}$, en tercer lugar, si dichas facultades se modifican cuando se trata de una epidemia como la que presenciamos.

Para atender el primero punto basta con revisar el catálogo establecido en el artículo 3o. de la LGS para observar que las enfermedades transmisibles sí son consideradas materia de salubridad general. ${ }^{1}$ Las enfermedades transmisibles se encuentran especificadas a su vez en listado específico, el cual incluye a la influenza epidémica, infecciones agudas del aparato respiratorio, infecciones meningocócicas y las enfermedades causadas por estreptococos, entre otras. A dicho listado pueden incorporarse aquellas enfermedades que determine el Consejo de Salubridad General o que sean reconocidas de conformidad a los tratados y convenciones internacionales en que México sea parte. ${ }^{2}$

La atención de las enfermedades transmisibles se realiza a partir de tres actividades: vigilancia epidemiológica, prevención y control. ${ }^{3}$ La concurrencia en cada una de estas actividades es distinta.

\footnotetext{
Artículo 3o., fracción XV de la Ley General de Salud.

2 Artículo 134 de la Ley General de Salud.

3 Idem.
} 
Este libro forma parte del acervo de la Biblioteca Jurídica Virtual del Instituto de Investigaciones Jurídicas de la UNAM

Las actividades de vigilancia epidemiológica son preponderantemente federales. La Secretaría de Salud es la encargada de establecer y operar el Sistema Nacional de Vigilancia Epidemiológica (SINAVE). ${ }^{4}$ Mientras que la difusión, aplicación y verificación del cumplimiento de los procedimientos de la vigilancia corresponde a los Estados. ${ }^{5}$ Por su parte, las actividades de prevención y control de las enfermedades transmisibles les competen principalmente a las entidades federativas, pues en ellas recae el deber de organizar, operar, supervisar y evaluar dichas actividades. ${ }^{6}$ Respecto a estas dos actividades, las facultades de la federación se acotan a la elaboración de programas o campañas temporales o permanentes, en coordinación con las autoridades estatales. $^{7}$

Guando una enfermedad se presenta como brote o epidemia, existe la obligación de notificar inmediatamente a la Secretaría de Salud federal o a la autoridad sanitaria más cercana. ${ }^{8}$ La LGS faculta a las autoridades sanitarias a utilizar como elementos auxiliares los recursos médicos existentes en las regiones afectadas, ${ }^{9} \mathrm{y}$ a ordenar, por causas de epidemia, la clausura temporal de los locales o centros de reunión de cualquier índole. ${ }^{10}$ La ley emplea el término "autoridades sanitarias" sin especificar si se alude a las de carácter federal o local, lo cual inicialmente podría llevar a considerar que se trata de facultades que pueden ser ejercidas indistintamente en forma de concurrencia. Sin embargo, por tratarse de facultades para la prevención y el control de enfermedades transmisibles, debe considerarse que éstas les corresponden a las entidades federativas bajo la coordinación de la Federación siempre que no sean consideradas como graves.

Un régimen competencial distinto se prevé cuando una epidemia adquiere ciertas características. En caso de que el fenómeno sea considerado como una epidemia de carácter grave, exista el riesgo de que una enfermedad transmisible invada el país o surja una situación de emergencia o una catástrofe que afecten al país, la LGS establece la "acción extraordinaria en materia de salubridad general" (AEMSG). ${ }^{11}$ La misma corresponde a la Secretaría de Salud. ${ }^{12}$ En este sentido, entre las responsabilidades de la au-

\footnotetext{
4 Ibidem, artículo 133, fracción II.

5 5.4 NOM-017-SSA2-2012, Para la vigilancia epidemiológica.

6 Artículo 13, apartado B, fracción I, Ley General de Salud.

7 Ibidem, artículo 135.

8 Ibidem, artículo 136, fracción II.

9 Ibidem, artículo 148.

10 Ibidem, artículo 152.

11 Ibidem, artículo 181.

12 Ibidem, artículo 13, apartado A, fracción V, en relación con el artículo 184.
} 
Este libro forma parte del acervo de la Biblioteca Jurídica Virtual del Instituto de Investigaciones Jurídicas de la UNAM

toridad sanitaria federal se encuentra encomendar a todas las autoridades federales, locales y municipales las actividades que se estimen necesarias para llevarla a cabo. ${ }^{13}$

El inicio de la AEMSG requiere de actos jurídicos concretos según el supuesto de la ley que se actualice. Así tratándose de una epidemia de carácter grave o del riesgo de que una enfermedad transmisible invada el país, corresponde exclusivamente al Consejo de Salubridad General emitir la declaratoria correspondiente. ${ }^{14}$ Cuando se trata de situaciones de una emergencia o una catástrofe que afecte al país, el mecanismo no es del todo claro, pues en caso de que dicha situación atente contra la seguridad nacional corresponde al Consejo de Salubridad General hacer la declaratoria en los términos de su reglamento interior, mientras que en los casos en que no se considere comprometida la seguridad nacional, corresponde al Ejecutivo Federal emitir la declaratoria de emergencia conforme al marco normativo en materia de protección civil, ${ }^{15}$ así como decretar la región o regiones amenazadas y el lapso que durará la AEMSG. ${ }^{16}$

A partir de lo anteriormente expuesto podemos apreciar que las enfermedades transmisibles sí se encuentran reguladas por nuestro ordenamiento jurídico, y que las competencias para atenderlas se diferencian por las características que adquiera un brote o epidemia. Cuando se encuentra en condiciones que bien podemos llamar "normales", el régimen que predomina es el de las facultades concurrentes, en el cual la Federación procesa información y coordina algunos de los esfuerzos de prevención, y las entidades operan las actividades de prevención y control. Por el contrario, cuando el brote o epidemia adquiere características de gravedad, las competencias para la atención y respuesta son principalmente federales. A las autoridades de este orden de gobierno les corresponde emitir la declaratoria respecto al supuesto que se actualizó y ejercer la AEMSG.

\section{INSTITUCIONES PARA RESPONDER A UNA EPIDEMIA GRAVE}

Las implicaciones de una epidemia grave para los individuos y las comunidades han propiciado que, a lo largo de la historia, se adopten medidas que res-

\footnotetext{
13 Artículo 184, fracción I, de la Ley General de Salud.

14 Artículo 9o., fracción XVII, del Reglamento Interior del Consejo de Salubridad General.

15 Artículo 7o., fracción IV, en relación con el 2, fracción XXVI, ambos de la Ley General de Protección Civil.

16 Artículo 183 de la Ley General de Salud.
} 
Este libro forma parte del acervo de la Biblioteca Jurídica Virtual del Instituto de Investigaciones Jurídicas de la UNAM

trinjan su propagación, así como el establecimiento de normas e instituciones para hacerse cargo de las respuestas a estos fenómenos. ${ }^{17}$

Desde luego, México no es la excepción. Desde el movimiento de independencia a inicios del siglo XIX hasta la consumación de la revolución en el siglo XX, el país vivió los estragos de brotes epidémicos como viruela, fiebre amarilla, paludismo, tifo o sarampión, por mencionar solo algunos. ${ }^{18}$ Ello llevó a que durante ese periodo se creara el Consejo Superior de Salubridad y, posteriormente, el Constituyente de 1917 estableciera la permanencia del Consejo de Salubridad General y se creara el Departamento de Salubridad para concentrar en el ámbito federal las facultades para responder una epidemia de carácter grave.

El diputado constituyente José María Rodríguez manifestó la añeja preocupación del Estado mexicano por la salud pública al momento de la discusión y debate del artículo 90 constitucional. El médico militar solicitó el uso de la palabra para expresar la necesidad de que se contara con una dependencia específica que unificara la atención a los problemas de salud pública en todo el territorio nacional, dada la trascendencia social y económica de las epidemias:

Las enfermedades exóticas epidémicas en un momento dado pueden atacar grandes proporciones de la República, interrumpir de modo completo el tráfico y las relaciones interiores de Estado a Estado y las internacionales, cegando pasajeramente todas las fuentes de riqueza y de subsistencia nacional.

Para la lucha contra estas enfermedades, que es para lo que yo propongo que el control lo tenga el Ejecutivo; la práctica ha enseñado que solamente se ha obtenido resultado cuando personal directamente organizado y, por decirlo así, municionado, pertrechado y guiado por el Consejo de Salubridad ha sido el encargado de la campaña. En todas las campañas militares y otras, la unidad de mando y de dirección es la base principal del éxito. ${ }^{19}$

La propuesta no se incorporó al texto aprobado del artículo 90 constitucional. ${ }^{20}$ Sin embargo, el médico constituyente junto con 41 diputados más

17 Gostin, Lawrence, Public Health Law: Power, Duty and Restraint, University of California Press, 2a. ed., 2008, p. 425.

18 Ruíz, Leobardo et al., "Antecedentes y Evolución de la Salubridad Pública en el México Independiente", Memorias y prospectiva de las Secretarías de Estado: Secretaría de Salud, Instituto Nacional de Estudios Históricos de la Revoluciones de México, 2017, pp. 43-63.

19 Marván, Ignacio, Nueva Edición del Diario de Debates del Congreso Constituyente de 19161917, Suprema Corte de Justicia de la Nación, México, 2006, t. II, p. 1986.

20 "Art. 90. Para el despacho de los negocios del orden administrativo de la Federación, habrá un número de secretarios que establezca el Congreso por una Ley, la que distribuirá los negocios que han de estar a cargo de cada Secretaría". 
Este libro forma parte del acervo de la Biblioteca Jurídica Virtual del Instituto de Investigaciones Jurídicas de la UNAM

propuso la adición de cuatro bases a la fracción XVI del artículo $73 .{ }^{21}$ Estas bases tenían sustento en tres objetivos principales: la necesidad de contar con órganos para atender de manera rápida y eficaz los problemas de salud pública; que dichos órganos tuvieran los recurso para ejecutar sus acciones, y que tuvieran la capacidad de emitir disposiciones obligatorias para todo el territorio nacional..$^{22}$ La exposición de la iniciativa resaltó de nueva cuenta el papel de estos órganos en el combate a las epidemias:

Como si la autoridad sanitaria no tiene un dominio general sobre la salubridad de la República en todo el país, para dictar sus disposiciones y ponerlas en vigor, éstas dejarán de ser efectivas en un momento dado para evitar las consecuencias de contagios o invasión de enfermedades epidémicas de estado a estado o internacionales... por esto, los subscriptos sostenemos que la unidad sanitaria de salubridad debe ser general, debe afectar a todos los Estados de la República, debe llegar a todos los confines y debe ser acatada por todas las autoridades administrativas pues en los pueblos civilizados, sin excepción, la autoridad sanitaria es la única tiranía que se soporta en la actualidad pues es la única manera de librar al individuo de los contagios, a la familia, al Estado y a la nación. ${ }^{23}$

La propuesta fue bien recibida por la amplia mayoría del Congreso Constituyente creando así al Consejo de Salubridad General, así como al establecimiento del Departamento de Salubridad Pública. ${ }^{24}$

El Consejo de Salubridad General fue creado como un órgano con amplias facultades normativas, consultivas y ejecutivas para atender la salud pública del país. ${ }^{25}$ La ahora Secretaría de Salud fue ideada como el brazo

21 El término "bases" fue empleado por el doctor Rodríguez al hacer uso de la palabra; sin embargo, no especificó las razones por las cuales denominó de esa manera a los cuatro párrafos que propuso incluir.

22 Cossío, José Ramón y Sánchez, David J., El Consejo de Salubridad General en la Constitución mexicana de 1917, Memorias y prospectiva de las Secretarías de Estado: Secretaría de Salud, Instituto Nacional de Estudios Históricos de la Revoluciones de México, 2017, pp. 78 y 79

23 Marván, Ignacio, Nueva Edición del Diario de Debates del Congreso Constituyente de 1916 1917, Suprema Corte de Justicia de la Nación, México, 2006, t. II, pp. 1769 y 1770

24 La iniciativa aprobada por 143 diputados a favor y 3 en contra. Los votos en contra fueron emitidos por los ciudadanos Fajardo, Palma y Pastrana Jaimes.

25 Artículo 73. El Congreso tiene facultad...

XVI. Para dictar Leyes sobre ciudadanía, naturalización, colonización, emigración e inmigración y salubridad general de la República.

la. El Consejo de Salubridad General dependerá directamente del Presidente de la República, sin intervención de ninguna Secretaría de Estado, y sus disposiciones generales serán obligatorias en el país. 
Este libro forma parte del acervo de la Biblioteca Jurídica Virtual del Instituto de Investigaciones Jurídicas de la UNAM

operativo de las medidas que el Consejo adoptara en materia de salud pública y como encargada de atender los servicios de salud. En su conjunto, ambas instituciones fueron facultadas para atender de manera rápida y eficiente las necesidades de la República cuando se presentara una epidemia de carácter grave dentro del territorio nacional o cuando hubiera el peligro de que una de estas ingresara al país. Esta intención del Constituyente la vemos articulada en la LGS en la AEMSG.

\section{LA ATENCIÓN A LA EPIDEMIA DEL VIRUS SARS-COV-2 EN MÉXICO}

El primero de enero de 2020 la Organización Mundial de la Salud (OMS) estableció un Equipo de Apoyo a la Gestión de Incidentes derivado de la notificación que recibió de la Comisión Municipal de Salud de Wuhan, China, de un conjunto de casos de neumonía en la ciudad, mismos que posteriormente se determinó que fueron causados por un nuevo coronavirus, el SARS-CoV-2. ${ }^{26}$

El Director General de la OMS convocó al Comité de Emergencia del Reglamento Sanitario Internacional el 22 de enero, para que se tratara y le asesorara sobre el brote del nuevo coronavirus a fin de decidir si se debía declarar una emergencia de salud pública de importancia internacional (ESPII). ${ }^{27}$ En dicha sesión no hubo consenso sobre si se trataba o no de una ESPII, por lo que se decidió que no lo era. ${ }^{28}$ Fue en la segunda sesión del Comité de Emergencia del Reglamento Sanitario Internacional realizada

2a. En caso de epidemias de carácter grave o peligro de invasión de enfermedades exóticas en el País, el Departamento de Salubridad tendrá obligación de dictar inmediatamente las medidas preventivas indispensables, a reserva de ser después sancionadas por el presidente de la República.

3a. La autoridad sanitaria será ejecutiva y sus disposiciones serán obedecidas por las autoridades administrativas del País.

26 "COVID-19: cronología de la actuación de la OMS" Organización Mundial de la Salud, 27 de abril de 2020, disponible en: https://wwre.who.int/es/news-room/detail/27-042020-who-timeline---covid-19.

27 El Reglamento Sanitario Internacional en su artículo 1o. define "emergencia de salud pública de importancia internacional" como aquellos eventos extraordinarios que: i) constituyen un riesgo para la salud pública de otros Estados a causa de la propagación internacional de una enfermedad, y ii) podría exigir una respuesta internacional coordinada.

28 Declaración sobre la reunión del Comité de Emergencia del Reglamento Sanitario Internacional (2005) acerca del brote de nuevo coronavirus (2019-nCoV), Organización Mundial de la Salud, 23 de enero de 2020, disponible en: https:/wwre.who.int/es/newes-room/ detail/23-01-2020-statement-on-the-meeting-of-the-international-health-regulations-(2005)-emergencycommittee-regarding-the-outbreak-of-novel-coronavirus-(2019-ncov) 
Este libro forma parte del acervo de la Biblioteca Jurídica Virtual del Instituto de Investigaciones Jurídicas de la UNAM

el 30 de enero de 2020, en que se reconoció al nuevo coronavirus como una ESPII, por ello recomendó que todos los países adoptaran las medidas de contención, como la vigilancia activa, la detección temprana, el aislamiento y el manejo de los casos, el seguimiento de contactos y la prevención. ${ }^{29}$

Conforme al marco constitucional y legal de nuestro país, la declaración de la OMS actualizó el supuesto de que existía "peligro de invasión de enfermedades exóticas", ${ }^{30}$ por lo que el Consejo de Salubridad General debió haber sesionado para hacer la declaración formal correspondiente y que la Secretaría de Salud ejerciera a partir de ese momento la AEMS. Sin embargo, esto no sucedió así. La primera acción oficial en torno a la pandemia no fue adoptada por las autoridades sanitarias sino por la Secretaría de Educación Pública (SEP). ${ }^{31}$ El 16 de marzo de 2020, la SEP suspendió las actividades educativas de todos los niveles - preescolar, primaria, secundaria, normal, medio superior y superior - a través de un Acuerdo publicado en el $D O F .^{32}$

Fue hasta el 19 de marzo que el Consejo de Salubridad General sesionó de manera extraordinaria para analizar la situación. Formalmente reconoció que la epidemia de enfermedad por el virus SARS-GoV2, como una enfermedad grave de atención prioritaria, mediante un Acuerdo publicado el 23 de marzo. ${ }^{33}$

29 Declaración sobre la segunda reunión del Comité de Emergencias del Reglamento Sanitario Internacional (2005) acerca del brote del nuevo coronavirus (2019-nCoV), Organización Mundial de la Salud, 30 de enero de 2020, disponible en: https://wrwre.who.int/es/ newes-room/detail/30-01-2020-statement-on-the-second-meeting-of-the-international-health-regulations(2005)-emergency-committee-regarding-the-outbreak-of-novel-coronavirus-(2019-ncov).

30 Artículo 73, fracción XVI, 2, constitucional, en relación con el artículo 181 de la Ley General de Salud.

31 Por acción oficial nos referimos a aquellos actos jurídicos publicados en los medios de difusión oficial del Estado, como lo es el Diario Oficial de la Federación. La Secretaría de Salud federal anunció en una conferencia de prensa realizada el 14 de marzo la "Jornada Nacional de Sana Distancia"; sin embargo, esta no fue publicada formalmente hasta el 31 de marzo siguiente.

32 Acuerdo número 02/03/20 por el que se suspenden las clases en las escuelas de educación preescolar, primaria, secundaria, normal y demás para la formación de maestros de educación básica del sistema educativo nacional, así como aquellas de los tipos medio superior y superior dependientes de la secretaría de educación pública, 16 de marzo de 2020, Diario Oficial de la Federación. Inicialmente la suspensión comprendía del 23 de marzo al 17 de abril de 2020. El 1o. de abril se modificó el Acuerdo ampliando el periodo de suspensión al 30 de abril. La suspensión de actividades de amplió una vez más hasta el 30 de mayo.

33 Acuerdo por el que el Consejo de Salubridad General reconoce la epidemia de enfermedad por el virus SARS-CoV2 (COVID-19) en México, como una enfermedad grave de atención prioritaria, así como se establecen las actividades de preparación y respuesta ante dicha epidemia. Diario Oficial de la Federación del 23 de marzo de 2020. 
Este libro forma parte del acervo de la Biblioteca Jurídica Virtual del Instituto de Investigaciones Jurídicas de la UNAM

Al día siguiente, la Secretaría de Salud publicó las medidas preventivas que se debían implementar para la mitigación y control de los riesgos para la salud que implica la enfermedad por el virus SARS-CoV2. ${ }^{34}$ El Presidente de la República sancionó favorablemente las medidas ese mismo día, conforme a la facultad que le confiere el artículo 73, fracción XVI, 2, constitucional. ${ }^{35}$ Posteriormente, el Presidente ejerció la potestad del artículo 183 de la LGS para decretar la AEMSG en las regiones afectadas de todo el país - sin especificar cuáles eran estas - y algunas medidas para la adquisición de bienes y servicios para atender la emergencia.

En un hecho sin precedentes, el 30 de marzo, el Consejo de Salubridad General declaró que la epidemia constituía una "emergencia sanitaria por causa de fuerza mayor" ${ }^{36}$ terminología que no corresponde a la legislación sanitaria, sino que obedeció a una medida para evitar que se actualizarán los supuestos de suspensión de labores previstos en la Ley Federal del Trabajo. ${ }^{37}$ Con ello, sin embargo, se actualizaron muchas de las implicaciones que la fuerza mayor ocasiona en otro tipo de relaciones jurídicas, como claramente son las civiles y las comerciales.

Derivado del acuerdo anterior, la Secretaría de Salud declaró nuevas acciones extraordinarias ${ }^{38}$ entre ellas, una clasificación de actividades y la suspensión de aquellas que no eran consideradas esenciales. ${ }^{39}$ Adicionalmente, modificó la integración del Consejo de Salubridad General. ${ }^{40}$ A di-

34 Acuerdo por el que se establecen las medidas preventivas que se deberán implementar para la mitigación y control de los riesgos para la salud que implica la enfermedad por el virus SARS-GoV2 (COVID-19), Diario Oficial de la Federación del 24 de marzo de 2020.

35 Decreto por el que se sanciona el Acuerdo por el que se establecen las medidas preventivas que se deberán implementar para la mitigación y control de los riesgos para la salud que implica la enfermedad por el virus SARS-CoV2 (COVID-19), Diario Oficial de la Federación del 27 de marzo de 2020.

36 Acuerdo por el que se declara como emergencia sanitaria por causa de fuerza mayor, a la epidemia de enfermedad generada por el virus SARS-GoV2 (COVID-19), Diario Oficial de la Federación del 30 de marzo de 2020.

37 Artículo 42 bis, en relación con el 429, fracción IV, de la Ley Federal del Trabajo.

38 Acuerdo por el que se establecen acciones extraordinarias para atender la emergencia sanitaria generada por el virus SARS-CoV2, Diario Oficial de la Federación del 31 de marzo de 2020.

39 La suspensión de actividades se acordó hasta el 30 de abril. Sin embargo, dicha disposición fue modificada el 21 de abril por lo que se amplió el plazo hasta el 30 de mayo de 2020.

$40 \mathrm{Al}$ respecto cabe mencionar que se trató de una modificación ilegal al Reglamento Interior del Consejo de Salubridad General, pues dicho ordenamiento solo podría haber sido modificado bajo el mismo procedimiento por el cual se creó. Dicha situación parece que fue advertida por la Secretaría de Salud, pues el 3 de abril de 2020, publicó una nota 
Este libro forma parte del acervo de la Biblioteca Jurídica Virtual del Instituto de Investigaciones Jurídicas de la UNAM www.juridicas.unam.mx

ferencia de lo que aconteció con las acciones adoptadas el 24 de marzo, en esta ocasión las medidas no fueron sancionadas por el Presidente de la República.

El 3 de abril, la Secretaría de Salud dio contenido al Decreto presidencial del 27 de marzo para garantizar las acciones de respuesta a la epidemia. ${ }^{41}$ En particular se facultó a distintas dependencias para la adquisición de bienes y servicios, se posibilitó también la contratación de médicos y se suprimieron trámites administrativos para la importación de bienes. ${ }^{42}$

El 21 de abril de 2020, la Secretaría de Salud modificó y adicionó el acuerdo del 31 de marzo. Se incorporaron a su contenido cuatro artículos. En ellos, la Secretaría de Salud Federal decidió que definiría los criterios para evaluar la intensidad de la transmisión del virus SARS-CoV2 y que establecería los lineamientos para reducir la movilidad entre los municipios con distinto grado de propagación. ${ }^{43}$

Además, determinó que realizaría las adecuaciones que considerase necesarias al Sistema de Vigilancia Epidemiológica y delegó a las Entidades Federativas su responsabilidad para instrumentar las medidas de prevención y control, ${ }^{44}$ así como la establecimiento y ejecución de mecanismos para la reducción de la movilidad de los habitantes entre municipios, ello a partir de lineamientos expedidos por la Secretaría de Salud Federal. ${ }^{45}$

El pasado 14 de mayo comenzó - jurídicamente hablando - la denominada "nueva normalidad". Para ello, la Secretaría de Salud emitió un Acuerdo cuyo objeto fue establecer la estrategia para la reapertura de

aclaratoria en el Diario Oficial de la Federación en la cual cambió el sentido del artículo Segundo del Acuerdo publicado originalmente.

41 Acuerdo por el que se establecen acciones extraordinarias que se deberán de realizar para la adquisición e importación de los bienes y servicios a que se refieren las fracciones II y III del artículo segundo del Decreto por el que se declaran acciones extraordinarias en las regiones afectadas de todo el territorio nacional en materia de salubridad general para combatir la enfermedad grave de atención prioritaria generada por el virus SARS-CoV2 (COVID-19), publicado el 3 de abril de 2020 en el Diario Oficial de la Federación.

42 Las especificaciones que debían observar las dependencias facultadas fueron publicadas de manera posterior, en un Acuerdo de la Secretaría de Salud del 24 de abril de 2020.

43 "Acuerdo por el que se modifica el similar por el que se establecen acciones extraordinarias para atender la emergencia sanitaria generada por el virus SARS-CoV2, publicado el 31 de marzo de 2020", 21 de abril de 2020, Diario Oficial de la Federación.

44 "Acuerdo por el que se modifica el similar por el que se establecen acciones extraordinarias para atender la emergencia sanitaria generada por el virus SARS-GoV2, publicado el 31 de marzo de 2020", 21 de abril de 2020, Diario Oficial de la Federación.

45 Los lineamientos referidos en el Acuerdo no fueron publicados en el Diario Oficial de la Federación, ni constan en el sitio web habilitado por el Gobierno Federal con motivo de la Epidemia. 
Este libro forma parte del acervo de la Biblioteca Jurídica Virtual del Instituto de Investigaciones Jurídicas de la UNAM

las actividades sociales, educativas y económicas. El Acuerdo establecía las etapas en que se dará la reapertura de forma gradual, ordenada y cauta. Reconoció a la industria de la construcción, la minería y la fabricación de equipo de transporte como actividades esenciales. Asimismo, se estableció un sistema de semáforo para la adopción de medidas sanitarias, y que la Secretaría de Salud publicaría los municipios que podrían retomar todas sus actividades, para que en coordinación con las autoridades sanitarias de las entidades federativas se establecieran las medidas de prevención y control de GOVID-19. ${ }^{46}$

$\mathrm{Al}$ día siguiente, el Acuerdo fue modificado. En primer término, se cambió la manera en que las empresas debían adoptar las acciones de preparación para la reapertura, pues se añadieron supuestos no previstos inicialmente. Se obligó a las empresas a presentar protocolos de seguridad sanitaria acordes con los lineamientos generales que dispusieran las secretarías de Salud, de Economía y del Trabajo y Previsión Social y los lineamientos de seguridad sanitaria en el entorno laboral que publicaría la Secretaría de Salud, en coordinación con las dependencias referidas y el Instituto Mexicano del Seguro Social. ${ }^{47}$ Finalmente, el 29 de mayo de 2020 se dio a conocer el Acuerdo que contiene los lineamientos técnicos específicos que deberán ser implementados para la reapertura de las actividades económicas. ${ }^{48}$

La descripción anterior es una muestra general de lo que jurídicamente ha sido la respuesta del Estado a la epidemia del virus causante de COVID-19. Desde que se declaró formalmente su inicio las autoridades sanitarias federales han publicado diecisiete instrumentos en el Diario Oficial de la Federación mediante los cuales se ha intentado ordenar la respuesta a la

46 Acuerdo por el que se establece una estrategia para la reapertura de las actividades sociales, educativas y económicas, así como un sistema de semáforo por regiones para evaluar semanalmente el riesgo epidemiológico relacionado con la reapertura de actividades en cada entidad federativa, así como se establecen acciones extraordinarias, 14 de mayo de 2020, Diario Oficial de la Federación.

47 El 18 de mayo, se difundieron originalmente en la página web de la Secretaría de Salud los "Lineamientos Técnicos de Seguridad Sanitaria en el Entorno Laboral". Posteriormente, fueron trasladados a la página web de la Secretaría del Trabajo y Previsión Social. Formalmente parece que se trata de un Acuerdo del Secretario de Salud, quién los firmó el domingo 17 de mayo, sin embargo, nunca fueron publicados oficialmente. Los lineamientos son de aplicación obligatoria para las industrias de la construcción, la minería y la fabricación de equipo de transporte, y referente para resto de las actividades esenciales. Estos lineamientos contienen reglas de carácter técnico-sanitario que distintos sujetos deben observar para reiniciar sus actividades, pese a que se haya señalado que son actos de "buena voluntad".

48 Acuerdo por el que se establecen los Lineamientos Técnicos Específicos para la Reapertura de las Actividades Económicas, 29 de mayo de 2020, Diario Oficial de la Federación. 
Este libro forma parte del acervo de la Biblioteca Jurídica Virtual del Instituto de Investigaciones Jurídicas de la UNAM

epidemia. ${ }^{49}$ Sin embargo, las medidas no han logrado de manera eficiente su cometido por diversos factores.

En primer lugar, un mal entendimiento del marco normativo aplicable a una epidemia grave. Existió una dilación injustificada para que el Consejo de Salubridad General sesionara y declarara la existencia de un peligro de invasión de una enfermedad infecciosa. Transcurrieron 49 días entre la declaración por parte de la OMS acerca de que se trataba de una ESPII y la sesión del Consejo de Salubridad General. Si bien se indicó en diversas conferencias de prensa que existieron sesiones de otros órganos para revisar el estado de la epidemia, ninguno de estos resultaba el competente para declarar la emergencia y, con ello, comenzar la respuesta del Estado.

En segundo lugar, el marco normativo vigente debió ser interpretado de manera amplia, pues si bien la Constitución es clara que en cuanto al alcance de la medidas y disposiciones que surjan del Consejo de Salubridad General como de la Secretaría de Salud, la AEMSG prevista en la LGS únicamente delimita las competencias de la Secretaría de Salud federal para ordenar los ámbitos propios de la salubridad general. De ahí que la AEMGS resultase insuficiente para que la Secretaría de Salud pudiera normar la respuesta de toda la Administración Pública Federal a la epidemia. Por ello, debió adoptarse una interpretación bajo la cual el Consejo de Salubridad General, por su composición y su carácter técnico-científico, fuera el epicentro de las medidas que debían ser adoptadas por todas las autoridades del país.

En tercer lugar, derivado de los puntos anteriores, la falta de disposiciones que proporcionaran elementos normativos suficientes para que las entidades pudieran actuar en el ámbito de sus competencias y coordinarse con las autoridades federales. Ello generó vacíos normativos que propiciaron una mala coordinación entre la federación y los Estados. Además, poca claridad de las disposiciones emitidas abonó a este problema, pues en un momento dado la federación delegó indebidamente facultades exclusivas de instrumentación y ejecución de medidas, cuando la epidemia ya había avanzado.

Las consecuencias económicas y sociales de los problemas aquí apuntados, desafortunadamente, no las conoceremos por completo hasta que la epidemia concluya. Sin embargo, el estudio y análisis de lo que se hizo y dejo de hacer abre la oportunidad para que no vuelva repetirse.

49 Conteo realizado al 31 de julio de 2020. 
Este libro forma parte del acervo de la Biblioteca Jurídica Virtual del Instituto de Investigaciones Jurídicas de la UNAM

\section{CONCLUSiOnes}

La epidemia de SARS-CoV-2 no será la última que nos toque enfrentar. Por ello resulta necesario realizar las modificaciones necesarias a las normas para que se cuente con las herramientas jurídicas suficientes para actuar de manera rápida y eficiente. El mal entendimiento del marco normativo aplicable a una epidemia fue uno de los problemas que hemos precisado estos meses. Pueden existir distintas causas de esto. Una de ellas es la heterogeneidad en el uso del lenguaje de los distintos ordenamientos aplicables.

Veamos un ejemplo. La Constitución habla de "epidemias de carácter grave" o "peligro de invasión de enfermedades exóticas"; la LGS prevé, además, los conceptos de "situaciones de emergencia" o "catástrofe" y el Reglamento Interior del Consejo de Salubridad General habla de "causa de emergencia" o que "atenten contra la seguridad nacional".

Estas variaciones en el uso del lenguaje, aunque parezcan pequeñas no lo son, pues es a partir de ellas los titulares de los órganos toman decisiones y determinan si les compete o no atender una situación en particular, lo cual puede retrasar una respuesta efectiva. Prueba de ello, es el caso de las sesiones que sostuvieron el Comité Nacional para la Seguridad en Salud y el Comité Nacional de Emergencias con motivo de la epidemia de SARS$\mathrm{CoV}-2$ las cuales se desarrollaron aun cuando no eran los órganos competentes para ejercer la respuesta a este problema.

Otra de las causas a las que se puede atribuir el mal entendimiento que se tuvo del marco normativo, es que este se encuentra incompleto. La AEMSG prevista en la LGS únicamente cuenta con cuatro artículos, ninguno de los cuales no prevén las interacciones ni las intervenciones que tendrá toda la administración pública y de los distintos niveles de gobierno fuera del ámbito sanitario. En ese sentido, sería recomendable que un reglamento que dote de contenido a la AEMSG y del cual a su vez se desprendieran protocolos respuesta ante las distintas posibilidades del surgimiento de una epidemia grave. ${ }^{50}$

Un segundo aspecto a considerar derivado de la epidemia, es la necesidad de revisar el papel del Consejo de Salubridad General en la conducción de la respuesta a un fenómeno de esta naturaleza, pero a la vez de su rol en la conducción de la política pública en salud.

Hoy más que nuca, la salud pública requiere de un trabajo multidisciplinario coordinado en el que se empleen diversas herramientas que promuevan el bienestar individual y colectivo. Este trabajo debe encontrar sus bases

50 Von Aguilar, Lorena, Derecho y pandemias, Tirant lo Blanch, México, 2018, p. 65. 
Este libro forma parte del acervo de la Biblioteca Jurídica Virtual del Instituto de Investigaciones Jurídicas de la UNAM

en la evaluación, el desarrollo de políticas y en certificar que los objetivos se cumplan, para ello es importante que desde el derecho los órganos previstos para ello cuenten con los mecanismos necesarios para ejercer sus funciones. ${ }^{51}$

El Consejo de Salubridad General fue creado como un órgano colegiado con facultades amplias para la emisión de disposiciones obligatorias en materia de salud pública. Su participación en el diseño de políticas públicas en la materia es indispensable por su naturaleza técnica y científica. ${ }^{52}$

Lejos de que esta función constitucional del Consejo de Salubridad General se haya reforzado, con el paso de los años, en particular, con la aprobación de la LGS de 1984 se le han quitado facultades al grado de prácticamente dejarlo como un órgano consultivo con ciertas atribuciones para aprobar medicamentos y certificar instituciones.

No obstante, la reforma constitucional al artículo 4o. constitucional en materia de servicios de salud y la creación del Instituto Nacional de Salud para el Bienestar, se erigen como una oportunidad no solo de replantear los alcances que se pretende dar a los servicios de atención médica, sino también a las políticas públicas en materia de salud que se deseen emprender. ${ }^{53}$

Por ello, es indispensable contar con un Consejo de Salubridad General jurídicamente fuerte que recupere sus facultades históricas de conducción de la política pública mediante la expedición de reglamentos que las vuelvan exigibles a todas las autoridades. También, que sea la Secretaría de Salud la encargada de vigilar su cumplimiento.

Esta propuesta parte de la necesidad de que las políticas públicas surjan del conocimiento y del trabajo multidisciplinario generado dentro del Consejo, ya sea con su estructura actual - en la que participan distintas secretarías de estado - o con una diversa pero que conserve la pluralidad de perfiles de sus integrantes.

La mejor manera de prepararnos pare enfrentar otra epidemia como la que se ha vivido a lo largo del 2020 y para los distintos retos de salud pública derivados del cambio climático, del uso de nuevas tecnologías y de otros factores sociales, es teniendo un órgano suficientemente capacitado para ello y con un marco normativo suficientemente claro.

51 Thompson, Ed et al., "The Law and the public's health: Foundations" en Law in public health practice (coord. Goodman), 2a. ed., Oxford University Press, 2007, p. 27.

52 Consejo de Salubridad General, Análisis del marco jurídico del Consejo de Salubridad General, México, 2005, p. 103.

53 Decreto por el que se reforma y adiciona el artículo 4o. de la Constitución Política de los Estados Unidos Mexicanos, 8 de mayo de 2020, Diario Oficial de la Federación. 